Revue d'histoire de l'Amérique française

REVUE D.HISTOIRE DE L'AMÉRIQUE FRANÇAISE

\title{
LABERGE, Alain, dir., Histoire de la Côte-du-Sud. Québec, Institut québécois de recherche sur la culture, coll. « Les régions du Québec », nº 4, 1993.
}

\section{Serge Gagnon}

Volume 48, numéro 2, automne 1994

URI : https://id.erudit.org/iderudit/305335ar

DOI : https://doi.org/10.7202/305335ar

Aller au sommaire du numéro

Éditeur(s)

Institut d'histoire de l'Amérique française

ISSN

0035-2357 (imprimé)

1492-1383 (numérique)

Découvrir la revue

Citer ce compte rendu

Gagnon, S. (1994). Compte rendu de [LABERGE, Alain, dir., Histoire de la Côte-du-Sud. Québec, Institut québécois de recherche sur la culture, coll. « Les régions du Québec ", $\mathrm{n}^{0} 4$ 4, 1993.] Revue d'histoire de l'Amérique française, 48(2), 261-265. https://doi.org/10.7202/305335ar d'utilisation que vous pouvez consulter en ligne.

https://apropos.erudit.org/fr/usagers/politique-dutilisation/ 
LABERGE, Alain, dir., Histoire de la Côte-du-Sud. Québec, Institut québécois de recherche sur la culture, coll. «Les régions du Québec», $\mathrm{n}^{\mathrm{0}} 4,1993$.

Cet imposant essai de public history est le quatrième paru dans la collection Les régions du Québec, le meilleur peut-être des quatre histoires 
régionales parues à ce jour. À mon sens, la partie la mieux réussie concerne l'histoire économique et sociale. Dans l'ensemble, le lecteur est frappé par le développement inégal qui oppose l'espace riverain à l'arrière-pays. La lecture des rapports démographie et culture est plus discutable. Mais cette lacune reflète celles de la recherche historique en général, à l'exception de la région du Saguenay.

Au moment de la conquête, la région abritait environ $15 \%$ de la population québécoise. Un siècle plus tard, cette proportion a diminué de plus de la moitié. Les auteurs insistent sur les pressions démographiques à l'origine d'un exode dont ils ont peut-être exagéré l'ampleur, se fiant aux chiffres quelquefois peu fiables de Fernand Ouellet. La population régionale double entre 1760 et 1790 , et redouble dans les quarante années qui suivent. Écrire qu'à l'exception de Beaumont, Saint-Jean-Port-Joli et Saint-Gervais, «toutes les paroisses de la région [...] montrent un solde migratoire négatif» (p. 81), c'est ignorer qu'à Kamouraska, il n'y avait pas 1492 habitants en 1822 , mais entre quatre et cinq mille (4964, selon le rencensement de 1825). Voilà au moins une paroisse qui, à l'instar des trois autres, a non seulement retenu sa population mais accueilli des étrangers. Pour cette première moitié du $\mathrm{XIX}^{\mathrm{e}}$ siècle, est-il légitime de parler de monde plein? L'expression est empruntée aux Français qui l'appliquent à l'ensemble du territoire national. $\mathrm{Ne}$ valait-il pas mieux dire saturation de l'espace régional, compte tenu de la grande mobilité de l'écoumène québécois? Cette remarque en appelle une autre; il m'apparaît abusif d'écrire «la société de la Côte-du-Sud» (p. 172) ou «la société des comtés de la région» (p. 337). Pour en finir avec le vocabulaire, j'ai noté une coquille bien québécoise: il vaut mieux compter les individus, les habitants, que les «âmes» (p. 389)... enrobées de corps, comme disait Goubert.

On lira avec intérêt les pages sur la colonisation d'un arrière-pays limité par les frontières américaines. Cette extension de l'espace habité ne suffit pas à absorber les surplus démographiques. Les migrations au Québec et l'émigration aux États résorbent des tensions inévitables en l'absence de contraception. Les Canadiens errants de la chanson ont fait l'expérience de l'exil, à l'exemple de toutes les populations catholiques (Italiens, Irlandais, Polonais, Hispano-Portugais), moins la française. Je ne pense pas que la haute fécondité du temps ait eu pour cause le besoin d'une main-d'œuvre agricole abondante (p. 199), car d'autres populations ont su, à l'époque du machinisme et de la disponibilité d'un prolétariat rural, se passer d'une «progéniture importante», les Normands, par exemple.

En 1930, la population sud-côtoise (85 603), équivaut à $3 \%$ de la population du Québec. Dans la dernière séquence chronologique retenue (19301993), on continue de quitter cette région où la fécondité dépasse encore longtemps les moyens de subsistance. En 1993, les 93073 habitants ne forment plus que $1,35 \%$ de la population de la province. La contraception (première phase de la seconde révolution sexuelle occidentale) s'est diffusée avec peut-être un certain retard par rapport au Saguenay étudié par Gérard Bouchard. Les auteurs ignorent l'historiographie de la famille et de la sexualité qui a permis de mieux connaître la «génération lyrique» depuis 
l'avènement des anovulants. Ici comme ailleurs, mais moins tardivement qu'en Irlande, les catholiques ont mis du temps à réduire leur descendance, malgré le recul de la mortalité. C'est un trait original de la transition démographique en terre catholique.

Le déclin accéléré du taux de natalité accentue un vieillissement d'autant plus remarquable que l'espérance de vie a sensiblement augmenté depuis un demi-siècle. Le nombre de personnes de 60 ans et plus passe de 8,5\% en 1931 à 19,7 en 1991. Je partage le pessimisme des auteurs sur l'avenir d'au moins une partie du territoire (p. 387-389) qui se densifie, par ailleurs, autour de certains pôles de croissance urbaine anciens (Montmagny) ou récents (La Pocatière).

L'histoire économique régionale profite des progrès de la discipline dans l'institution savante. Les pratiques agricoles sud-côtoises obéissent au climat, à la qualité des sols. Ces contraintes physiques sont en partie responsables des régimes alimentaires humain et animal. J'ignorais que les pois servaient aussi à alimenter le porc (p. 101), que des pruniers et des pommiers «sauvages» poussaient dans les îles. Aux pages bien tournées sur la pêche côtière et l'économie agro-forestière avant 1850, succède l'étude de l'agriculture moderne. L'industrie laitière domine quelque temps, cependant que le machinisme pénètre plus lentement (première trayeuse mécanique en 1913) (p. 231) pour marquer des points dans l'après-guerre. Dans la sous-région côtière, une ferme sur trois possède un tracteur (400ss) au milieu des années 1950. L'histoire des productions des dernières décennies est celle d'une spécialisaton sous-régionale: élevage du porc dans Bellechasse et Montmagny, de la volaille dans l'Islet, élevage de l'agneau et maintien de l'industrie laitière dans l'est de la côte. Quelques spécialités horticoles (fraise, pomme) apparaissent. Pendant ce temps, la pêche commerciale, encore importante au $\mathrm{XIX}^{\mathrm{e}}$ siècle, devient une activité marginale; le savoir-faire de l'École supérieure de Pêcheries (La Pocatière, 1938-1963) profite aux pêcheurs du Golfe.

L'histoire de l'agriculture racontée ici n'est pas seulement celle des structures. Elle tient compte des fluctuations conjoncturelles. La chute des prix après la Première Guerre et durant les années 1930 entraîne des effets sur les structures: la hausse avait favorisé l'investissement qui se transforme en surendettement en période de faible demande.

L'arrière-pays vit à l'écart de cette agriculture marchande. Le travail en forêt y côtoie la pauvreté. L'industrie de transformation est à peu près tout entière localisée dans la sous-région des basses terres laurentiennes. L'histoire industrielle de la Côte nous apprend comment, et parfois pourquoi, telle entreprise émerge, pourquoi aussi elle disparaît, après avoir quelquefois procédé à des licenciements massifs. Le voyageur sans mémoire serait aujourd'hui étonné par la taille de l'agglomération de Saint-Pacôme. Sillonné par la Rivière-Ouelle, le village abritait des travailleurs de l'industrie du bois jusque vers le milieu du $\mathrm{XX}^{\mathrm{e}}$ siècle. Plus à l'ouest, Montmagny est la seule ville dont la vocation industrielle est centenaire. La Pocatière fournit l'exemple d'une petite ville de services dont la fonction industrielle est 
récente. Au cours des années 1960, un retraité à l'aise s'avise de fabriquer des motoneiges. Acquise par Bombardier en 1971, l'entreprise, spécialisée dans la fabrication de véhicules de transport ferroviaire et de wagons de métros, est aujourd'hui le plus gros employeur de la région (1 340 travailleurs en 1987).

J'ai beaucoup appris sur les structures d'encadrement, l'Église, la seigneurie, la municipalité, l'école, l'exercice de la fonction judiciaire. Je m'attarderai à l'institution catholique. L'Église sud-côtoise agit comme dispensatrice de services jusqu'à ce que l'État prenne la relève. Elle rassemble aussi des foules dans des expressions de foi exaltantes et exaltées (30 000 personnes au congrès marial de 1931 au collège de Sainte-Anne). Au milieu du siècle, s'amorçe un déclin qui nous mène à l'indifférence actuelle. L'histoire savante ne doit pas se faire complice des nostalgiques, mais expliquer en quoi la dynamique culturelle repose désormais sur d'autres forces.

Les études du ratio prêtre/fidèles, depuis les recherches pionnières de Louis-Edmond Hamelin, ont été plus ou moins explicitement inspirées par les autorités diocésaines. Ces commanditaires directs ou indirects ont infléchi les interprétations en direction des espoirs de survie de l'institution. Reprenant l'interprétation convenue, les auteurs évoquent le «manque de prêtres» qui commence à se faire sentir dans d'autres régions, dès le milieu du siècle. La Côte-du-Sud se distingue. Elle est encore aujourd'hui bien pourvue, même si l'âge moyen du clergé en exercice s'est sensiblement élevé. Aux défections des décennies antérieures, s'est ajoutée récemment une pénurie de recrues: une ordination en 1992 contre cinq en 1965. La chasteté perpétuelle n'attire plus, la révolution sexuelle a clairsemé les rangs des eunuques volontaires en vue du Royaume.

Je me demande ce que peut bien nous enseigner une statistique du ratio prêtre/fidèles de 1992 surtout lorsqu'elle est implicitement comparée à des proportions antérieures. L'évolution du nombre d'officiers doit être mise en parallèle avec les effectifs du régiment. Parmi le tiers des catholiques catégorie de recensement - qui continuent d'assister à la messe dominicale en 1990, très peu fréquentent le confessionnal, ou courent comme autrefois chercher le prêtre pour assister les mourants. La tâche pastorale a beaucoup changé, de sorte qu'il est difficile de raisonner sur l'offre et la demande de service, dans une perspective diachronique. Au cours des années 1960, les évêques actuels de La Pocatière et de Rimouski enseignaient respectivement la philosophie et la biologie au collège diocésain. Ils étaient pourtant comme bien des confrères, inclus dans le ratio prêtre/fidèles. Ils ont laissé la place à des laïcs pour s'occuper du troupeau. Combien en trente ans sont passés de l'enseignement à la pastorale? Combien aujourd'hui desservent plus d'une paroisse?

La Côte-du-sud continue certes, comme le reste du Québec, de réclamer le rituel funéraire catholique. Y a-t-il des exceptions? Dans quelle proportion la formation des couples fait-elle appel au rituel religieux? Le mariage civil y est-il plus fréquent qu'ailleurs? Le divorce plus, moins répandu? La nuptialité plus basse? Les couples sans engagement moins nombreux? 
L'exemption de la catéchèse rarissime? Des études récentes ont montré la pertinence de ces nouveaux indicateurs dont certains, il est vrai, ne peuvent être cernés sur une base régionale. Aussi, j'arrête l'énumération ayant conscience d'en demander beaucoup trop. Je ferai néanmoins remarquer que certaines statistiques régionales fournies par les rédacteurs, et quelquefois de simples adverbes désignant la fréquence, l'ampleur des phénomènes, ne permettent pas toujours de constater les écarts, s'ils existent, par rapport à d'autres régions. La comparaison avec la moyenne provinciale n'est pas toujours très utile en raison des distorsions qu'entraîne le poids démographique de Montréal. Le lecteur aimerait pouvoir comparer, par exemple, les taux de chômage, et le nombre relatif d'assistés sociaux (p. 499500) avec les chiffres de d'autres régions «périphériques».

Les auteurs ont été bien avisés de terminer leur œuvre par un chapitre substantiel sur la culture et, dans un premier temps, les créateurs, particulièrement nombreux en littérature. En marge de cette culture élitaire, dont le collège de Sainte-Anne a été le principal incubateur, s'est déployée une culture de consommation de masse dont les médias locaux se sont faits les intermédiaires et les promoteurs. La pénétration tardive des jouissances de la société de consommation est peut-être à mettre en parallèle avec un attachement plus solide qu'ailleurs à la culture catholique. Dans les dernières décennies, l'Église est devenue marginale parce que d'autres forces structurent les genres de vie. Tout au long de la lecture, se dégage l'hypothèse que la population sud-côtoise a renoncé plus tardivement que d'autres régions rurales à la joyeuse frugalité d'antan, avec ses familles nombreuses et le bonheur dans l'au-delà, pour accéder récemment aux paradis de la marchandise. Même la mémoire a été soumise aux lois du marché. Montrer, en terminant, que la conservation et l'animation du patrimoine sont reliées à l'industrie touristique et clore le tableau sur une invitation à peine voilée au touriste n'est pas le moindre mérite de ce livre, heureux compromis entre les attentes des commanditaires et du lectorat régional, et les exigences de l'écriture scientifique. 